\title{
SspA up-regulates gene expression of the LEE pathogenicity island by decreasing H-NS levels in enterohemorrhagic Escherichia coli
}

\author{
Anne-Marie Hansen ${ }^{1,2}$ and Ding Jun Jin ${ }^{1 *}$
}

\begin{abstract}
Background: Enterohemorrhagic Escherichia coli (EHEC) colonizes the intestinal epithelium and causes attaching and effacing (A/E) lesions. Expression of virulence genes, particularly those from the locus of the enterocyte effacement (LEE) pathogenicity island is required for the formation of a type three secretion system, which induces A/E lesion formation. Like other horizontally acquired genetic elements, expression of the LEE is negatively regulated by H-NS. In the non-pathogenic Escherichia coli K-12 strain the stringent starvation protein A (SspA) inhibits accumulation of H-NS, and thereby allows de-repression of the H-NS regulon during the stationary phase of growth. However, the effect of SspA on the expression of H-NS-controlled virulence genes in EHEC is unknown.

Results: Here we assess the effect of SspA on virulence gene expression in EHEC. We show that transcription of virulence genes including those of the LEE is decreased in an SsPA mutant, rendering the mutant strain defective in forming A/E lesions. A surface exposed pocket of SspA is functionally important for the regulation of the LEE and for the A/E phenotype. Increased expression of ler alleviates LEE expression in an SspA mutant, suggesting that the level of Ler in the mutant is insufficient to counteract H-NS-mediated repression. We demonstrate that the H-NS level is two-fold higher in an sspA mutant compared to wild type, and that the defects of the sspA mutant are suppressed by an hns null mutation, indicating that hns is epistatic to sspA in regulating H-NS repressed virulence genes.

Conclusions: SspA positively regulates the expression of EHEC virulence factors by restricting the intracellular level of H-NS. Since SspA is conserved in many bacterial pathogens containing horizontally acquired pathogenicity islands controlled by H-NS, our study suggests a common mechanism whereby SspA potentially regulates the expression of virulence genes in these pathogens.
\end{abstract}

Keywords: Enterohemorrhagic Escherichia coli, LEE, SspA, H-NS

\section{Background}

Enterohemorrhagic Escherichia coli (EHEC) O157:H7 is an emerging food- and waterborne- enteric pathogen causing diarrhea, hemorrhagic colitis and the potentially fatal complication hemolytic uremic syndrome in humans $[1,2]$. EHEC colonization of enterocytes of the large bowel is characterized by an intestinal attaching and effacing (A/E) histopathology, which is manifested by a localized degeneration of brush border microvilli and an intimate

\footnotetext{
* Correspondence: jind@mail.nih.gov

${ }^{1}$ Transcription Control Section, Gene Regulation and Chromosome Biology Laboratory, Frederick National Laboratory for Cancer Research, National Cancer Institute, National Institutes of Health, Frederick, MD 21702, USA Full list of author information is available at the end of the article
}

attachment of bacteria to actin-rich pedestal-like structures formed on the apical membrane directly beneath adherent bacteria [3]. The A/E lesion is due to the activity of a type III secretion system (T3SS) mainly encoded by the 35-45 kb locus of enterocyte effacement pathogenicity island (hereafter named LEE), which is conserved in some EHEC isolates and other A/E pathogens such as enteropathogenic Escherichia coli (EPEC), atypical EPEC, rabbit EPEC, Escherichia albertii and Citrobacter rodentium [4-7]. The LEE pathogenicity island comprises at least 41 genes that mainly are located in five major operons (LEE1-5). The LEE encodes a TTSS, translocator proteins, secreted effectors, regulators, an intimin (adhesin) and a translocated intimin receptor. The LEE-encoded

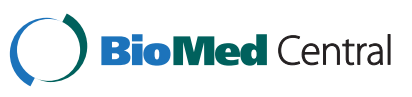


regulators Ler, Mpc, GrlR and GrlA are required for proper transcriptional regulation of both LEE- and nonLEE-encoded virulence genes in response to environmental cues [8-12].

The LEE was acquired by horizontal gene transfer [13] and is regulated by both generic E. coli- and pathogenspecific transcription factors. Consequently, the regulation of the LEE reflects characteristics of such genetic elements (For review see $[11,14])$. Silencing of xenogeneic DNA in bacterial pathogens under conditions unfavorable for infection is important to ensure bacterial fitness [15]. H-NS, which is an abundant pleiotropic negative modulator of genes involved in environmental adaptation and virulence [16-20], is a major silencing factor of horizontally acquired genes [21,22]. H-NS silences genes in the H-NS regulon by various mechanisms. Binding of $\mathrm{H}-\mathrm{NS}$ to regulatory regions of these genes prevents RNA polymerase from accessing and escaping from promoter DNA, which represents two different mechanisms used by $\mathrm{H}-\mathrm{NS}$ to silence gene expression (see [23-25] and references therein). H-NS is also a major transcriptional modulator of the LEE pathogenicity island, where it negatively affects the expression of LEE1-5, map and grlRA [26-31]. Further, H-NS binds to regulatory sequences upstream of virulence-associated genes located outside of the LEE including those encoding the long polar fimbriae (lpf) required for intestine cell adherence and enterohemolysin $(e h x)[32,33]$.

The expression of EHEC virulence genes including those encoded by the LEE is derepressed from the $\mathrm{H}-\mathrm{NS}$-mediated transcriptional silencing under physiological conditions that EHEC encounters during infection. Also, LEE expression is growth phase-dependent with maximum expression in early stationary phase [34]. H-NS-mediated silencing of transcription is overcome by the action of DNA-binding $\mathrm{H}-\mathrm{NS}$ paralogues such as the LEE1-encoded global transcriptional regulator Ler (For review see [35]). Ler promotes the expression of many $\mathrm{H}-\mathrm{NS}$-repressed virulence genes including those of LEE1-5, $\operatorname{grlRA}$ and non-LEE-encoded virulence genes such as lpf and the virulence plasmid pO157-encoded mucinase stcE $[26,28,31,36-39]$. Thus, Ler antagonizes H-NS in the regulation of many virulence genes, which belong to both the $\mathrm{H}-\mathrm{NS}$ and Ler (H-NS/Ler) regulons.

The E. coli stringent starvation protein A ( $\mathrm{SspA})$ is a RNA polymerase-associated protein [40] that is required for transcriptional activation of bacteriophage P1 late genes and is important for survival of $E$. coli K-12 during nutrient depletion and prolonged stationary phase [41-43]. Importantly, SspA down-regulates the cellular H-NS level during stationary phase, and thereby derepress the $\mathrm{H}-\mathrm{NS}$ regulon including genes for stationary phase induced acid tolerance in E. coli K-12 [44]. A conserved surface-exposed pocket of SspA is important for its activity as a triple alanine substitution P84A/H85A/ P86A in surface pocket residues abolishes SspA activity [45]. SspA is highly conserved among Gram-negative pathogens [44], which suggests a role of SspA in bacterial pathogenesis. Indeed, SspA orthologs affect the virulence of Yersinia enterocolitica, Neisseria gonorrhoeae, Vibrio cholerae, Francisella tularensis and Francisella novicida [46-51]. Since E. coli K-12 SspA is conserved in EHEC where H-NS negatively modulates virulence gene expression, we asked the question of whether SspA-mediated regulation of H-NS affects EHEC virulence gene expression. Here we study the effect of SspA on the expression of LEE- and non-LEE-encoded virulence genes and its effect on H-NS accumulation in EHEC. Our results show that in an $s s p A$ mutant elevated levels of $\mathrm{H}$-NS repress the expression of virulence genes encoding the T3SS system rendering the cells incapable of forming $\mathrm{A} / \mathrm{E}$ lesions. Thus, our data indicate that SspA positively regulates stationary phase-induced expression of $\mathrm{H}$-NS-controlled virulence genes in EHEC by restricting the H-NS level.

\section{Results and discussion}

\section{SspA positively affects transcription of EHEC virulence} genes

To evaluate the effect of $\operatorname{ssp} A$ on virulence gene expression in EHEC during the stationary phase we constructed an in-frame deletion of sspA in the E. coli O157:H7 strain EDL933 ATCC 700927 [52] and measured transcription of LEE- (LEE1-5, grlRA and map) and non-LEE-encoded (stcE encoded by pO157) genes (Figure 1). Wild type and sspA mutant strains were grown in LB medium to stationary phase with similar growth rates (data not shown). Total RNA was isolated and transcript abundance was measured by primer extension analyses using labeled DNA oligos specific to each transcript of interest and $о m p A$, which served as internal control for total RNA levels. Results revealed that transcript levels of LEE1-5, grlRA, map and $s t c E$ were reduced by up to 8 -fold in the sspA mutant compared to wild type (Figure 1A-H, lanes 1 and 2). The expression of these genes was restored when the $\operatorname{ssp} A$ mutant was supplied with wild type sspA in trans from pQEsspA [43] (Figure 1A-H, lane 3). However, the expression of ler and other virulence genes tested ( $\operatorname{rrlRA}$, espZ, sepL and stcE) remained repressed when the $s s p A$ mutant strain was supplied with mutant $s s p A$ from pQEsspA84-86 [45], which expresses SspA containing the tri-ple alanine substitution in the surface-exposed pocket (Figure 1I and data not shown). These results indicate that SspA positively affects stationary phase-induced expression of both LEE- and non-LEE-encoded virulence genes in EHEC. Moreover, the mode of action of SspA is likely similar in E. coli $\mathrm{K}-12$ and EHEC as the surface-exposed 

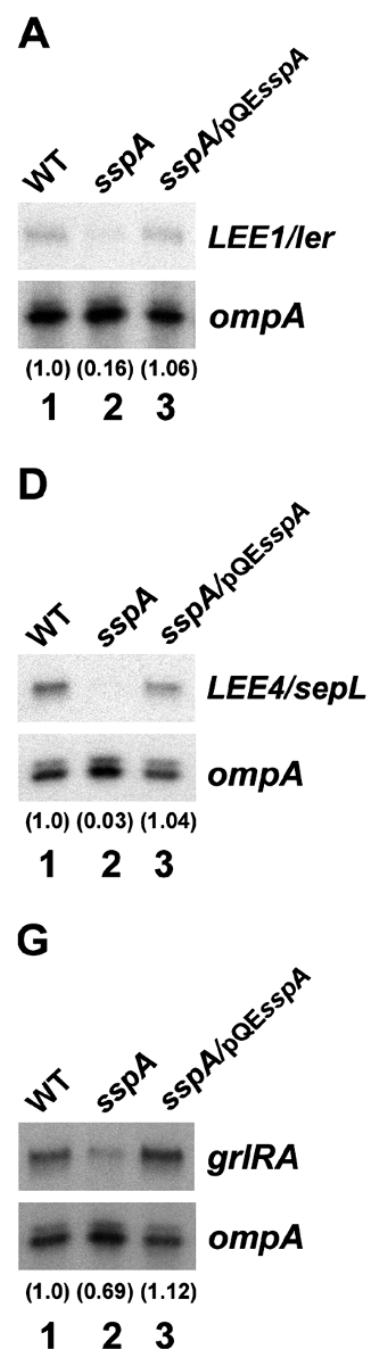
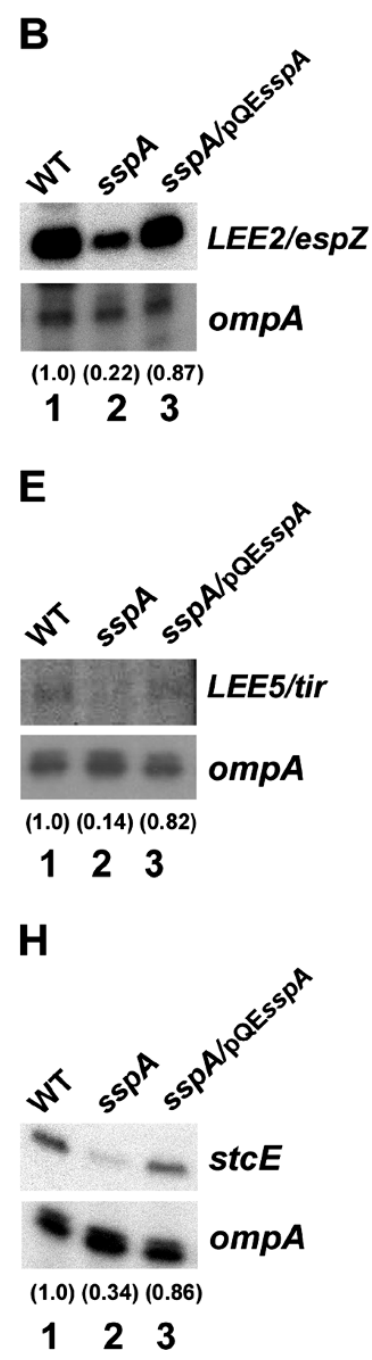
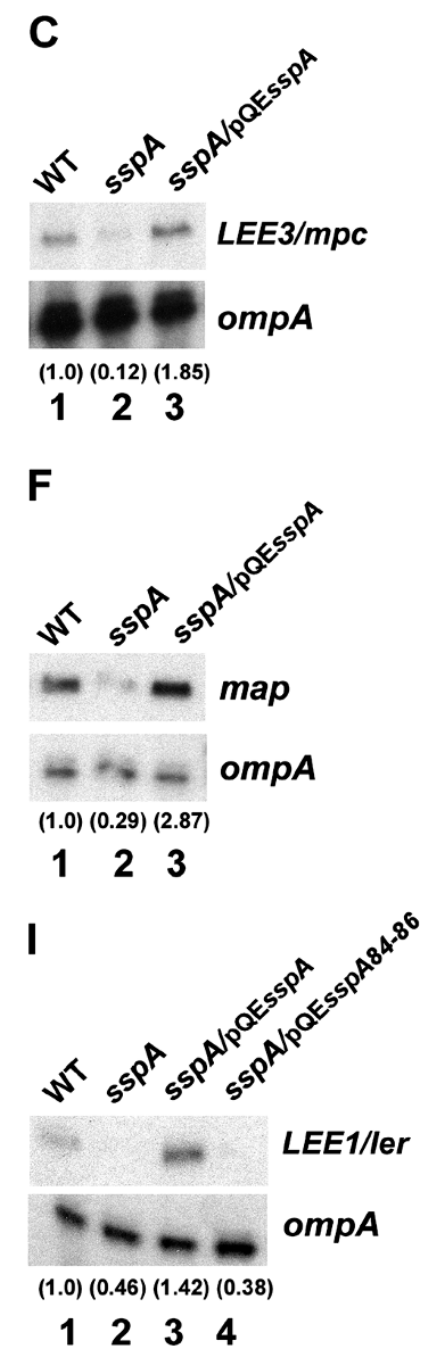

Figure 1 SspA positively affects LEE expression in stationary phase cells. Primer extension analyses on total RNA extracted from wild type EHEC EDL933 (lane 1), the sspA mutant (lane 2) and the sspA mutant complemented with wild type sspA (lane 3) or mutant sspA84-86 (lane 4) as indicated, grown in $L B$ at $37^{\circ} \mathrm{C}$ to stationary phase $\left(\mathrm{OD}_{600} \sim 3.0\right)$. The Labeled DNA oligos specific to the transcripts of $L E E 1 /$ ler $(\mathbf{A}$ and $\mathbf{I})$, $L E E 2 /$ espZ (B), LEE3/mpc (C), LEE4/sepL (D), LEE5/tir (E), map (F), grlRA (G) and stcE (H) were used. The ompA transcripts, detected with a labeled ompAspecific DNA oligo, served as internal control for the primer extension reaction. Wild type and mutant SspA were expressed from pQEsspA and PQEsspA84-86 respectively in the absence of induction at similar levels. The transcripts $L E E 1-5$, map, grlRA, stcE and the control transcript ompA are indicated. The relative transcript levels of target genes normalized to that of ompA are indicated by the numbers in parenthesis.

pocket of SspA also is required for SspA to affect the expression of EHEC virulence genes.

\section{Increased expression of ler enhances expression of} virulence genes in the sspA mutant

A decreased expression of ler in the $s s p A$ mutant (Figure 1A) could account for the apparent transcriptional repression of LEE2-5, grlRA, map and stcE (Figure 1B-H) because Ler positively controls those genes. Thus, we examined whether supplying ler in trans from the plasmid pACYCler would alleviate the expression of Ler-regulated genes in an $\operatorname{ssp} A$ mutant (Figure 2). Our results showed that transcript levels of $L E E 1, L E E 2, L E E 4, \operatorname{grlRA}$ and $s t c E$ were all increased in the $\operatorname{ssp} A$ mutant harboring $\mathrm{pACYCler}$ and exceeded that in wild type with up to about 9-fold (Figure 2A-E, compare lanes 1 and 3). These results are consistent with the explanation that a reduced expression of ler in the sspA mutant leads to an insufficient amount of Ler to antagonize H-NS-mediated repression of those virulence genes.

SspA activates virulence gene expression by reducing the H-NS level

Reduced virulence gene expression during the stationary phase could also be due to an increased level of $\mathrm{H}-\mathrm{NS}$ in the EHEC sspA mutant as observed for H-NS-regulated 

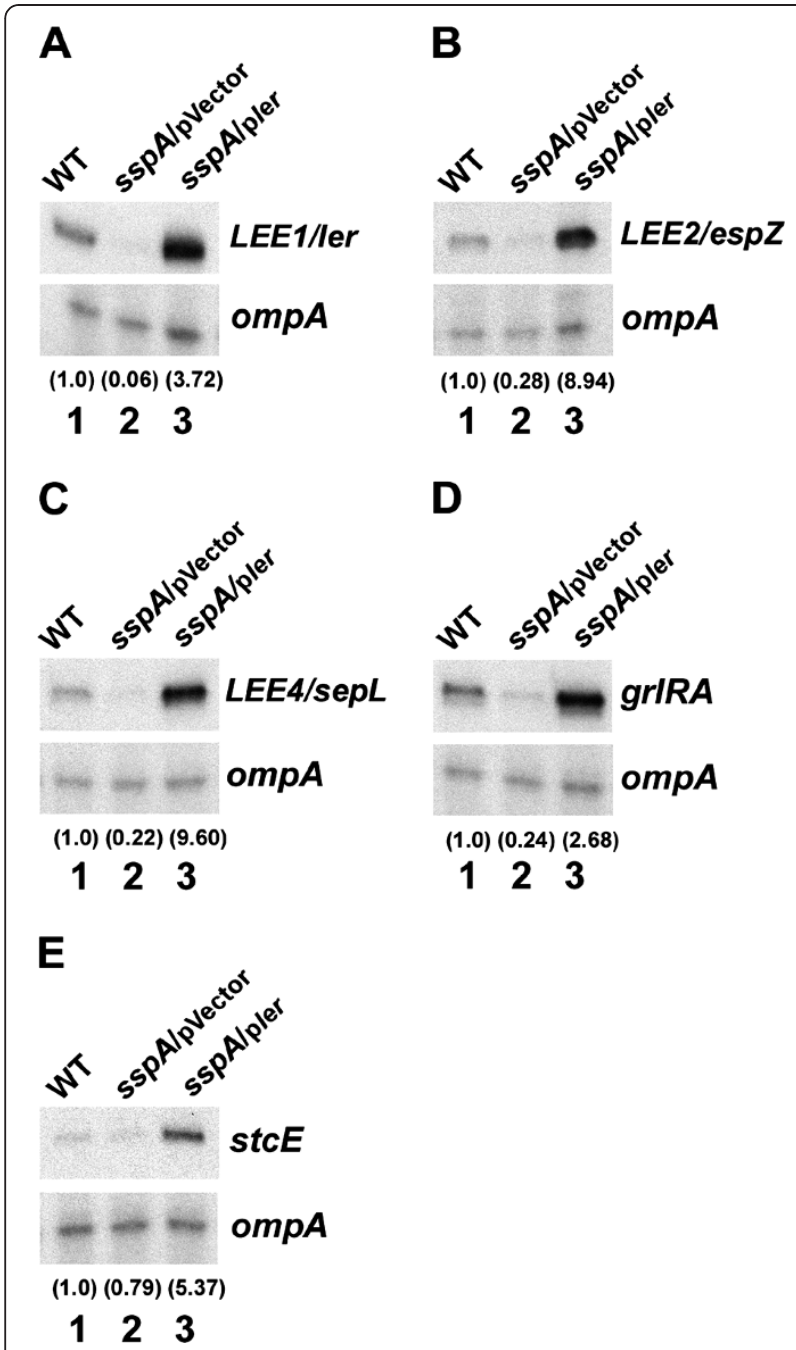

Figure $\mathbf{2}$ Increased ler expression overcomes repression of LEE in an sspA mutant. The expressions of virulence genes in wild type EHEC EDL933 (lane 1), the sspA mutant harboring the empty vector pACYC184 (pVector) (lane 2) and pACYCler (pler) expressing ler from its native promoters (lane 3 ) were determined by primer extension analyses using labeled DNA oligos specific to LEE1/ler (A), LEE2/espZ (B), LEE4/sepL (C), grlRA (D) and stcE (E) along with the ompA-specific oligo as a control. Samples were prepared and analyzed as described in the legend of Figure 1. The relative transcript levels of target genes normalized to that of ompA are indicated by the numbers in parenthesis.

genes in the E. coli $\mathrm{K}-12 \operatorname{ssp} A$ mutant [44]. We measured the levels of H-NS in stationary phase cells of wild type and $s s p A$ mutant EHEC strains by western analysis (Figure 3). Indeed, the H-NS level was two-fold higher in the sspA mutant than in the wild type, whereas the level of Fis as a control was not increased in the mutant compared to wild type. These results indicate that SspA activates the expression of EHEC virulence genes by decreasing accumulation of H-NS. Notably, such relative small change in H-NS levels was previously demonstrated to drastically affect the expression of the H-NS regulon

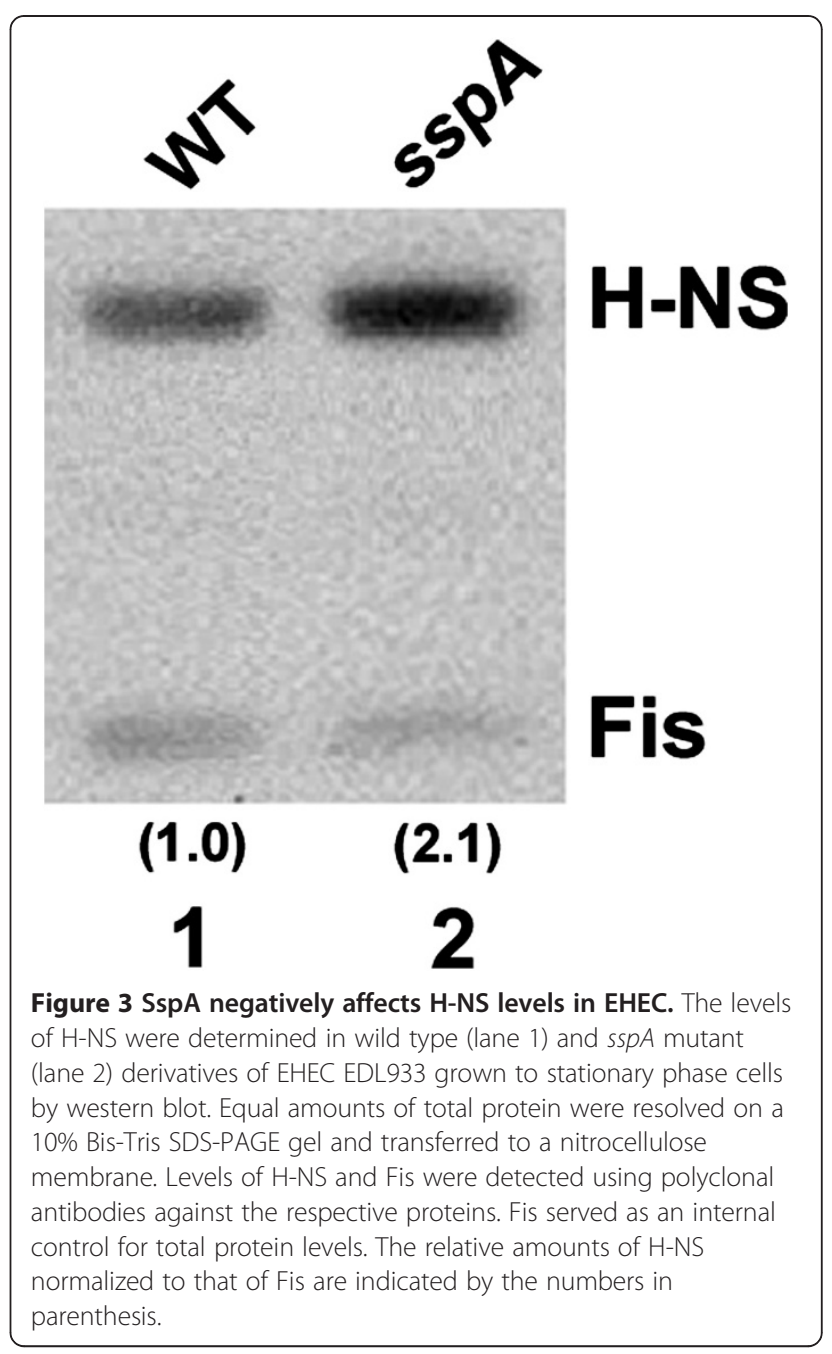

involved in stationary phase-induced acid tolerance of E. coli $\mathrm{K}-12$ [44].

Genetic analysis further indicated that hns mainly is epistatic to $\operatorname{ssp} A$ in regulating H-NS-repressed virulence genes in EHEC (Figure 4). We deleted hns in EHEC wild type and sspA mutant strains as described in Methods. The EHEC hns mutant derivatives had a mucoid phenotype and a longer generation time (g) than wild type ( $g$, wT $\sim 27, g_{\text {,hns }} \sim 36 \mathrm{~min}$ and $g$,hns,sspA $\left.\sim 45 \mathrm{~min}\right)$. Therefore, at least two independent clones of each hns mutant derivative were used in each experiment to ensure reproducible results. The expression of LEE1-5, grlRA, map and $s t c E$ was between 4 and 26-fold higher in an isogenic hns null mutant than in wild type (Figure $4 \mathrm{~A}-\mathrm{H}$, compare lane 3 with 1), which is consistent with the fact that there is enough H-NS in stationary phase wild type cells (Figure 3 ) to partially repress those virulence genes. Although the effect of hns on cell growth will be complex, an uncontrolled expression of the LEE genes and the T3SS is likely to be detrimental to the fitness of the cell [15]. Moreover, the expression level of EHEC virulence genes in the hns 
A

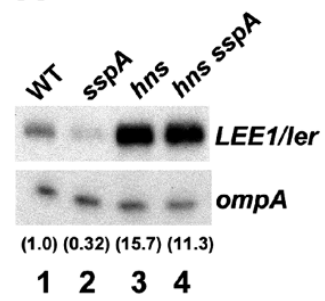

E

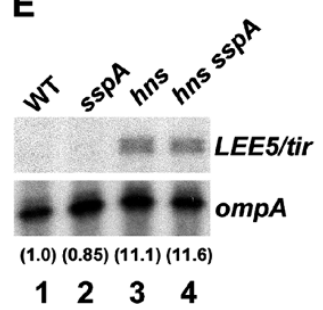

B

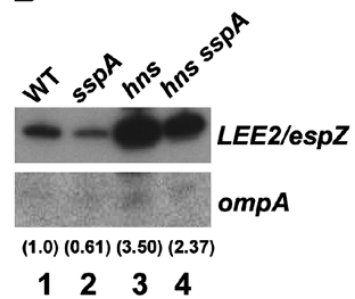

$\mathbf{F}$

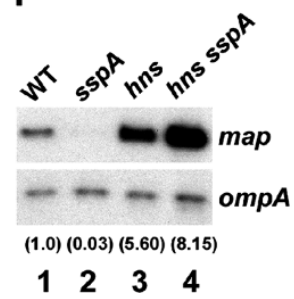

C

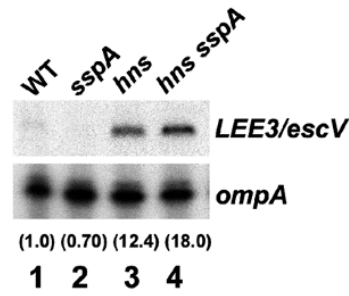

G

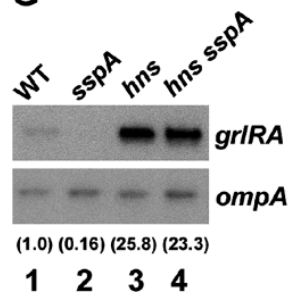

D

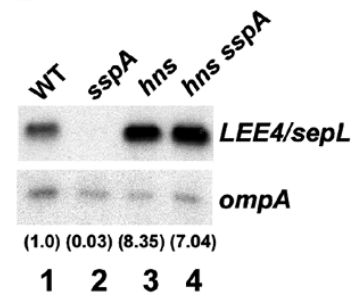

H

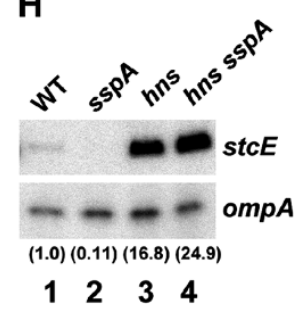

Figure $4 \mathrm{SspA}$ is upstream of H-NS in the regulatory network of virulence gene expression in EHEC. The expression of virulence genes in wild type EHEC EDL933 (lane 1), sspA (lane 2), hns (lane 3) and hns sspA (lane 4) mutant derivatives was determined by primer extension analyses using labeled DNA oligos specific to the transcripts of LEE1/ler (A), LEE2/espZ (B), LEE3/mpC (C), LEE4/sepL (D), LEE5/tir (E), map (F), grlRA (G) and $\operatorname{stcE}(\mathbf{H})$. In each reaction, the ompA transcript served as an internal control. Samples were prepared and analyzed as described in the legend of Figure 1. The relative transcript levels of target genes normalized to that of ompA are indicated by the numbers in parenthesis.

$\operatorname{ssp} A$ double mutant was within the range of the level observed for the hns single mutant (Figure 4A-H, compare lane 4 with 3). Thus, our data strongly indicate that SspA is located upstream of $\mathrm{H}-\mathrm{NS}$ in the regulatory cascade controlling the virulence gene expression in EHEC. However, SspA might also directly activate virulence gene expression in addition to controlling H-NS levels.

\section{SspA is required for cell adherence and $A / E$ lesion formation}

Since the expression of LEE-encoded genes involved in A/E lesion formation was decreased in a $\operatorname{ssp} A$ mutant and increased in a hns sspA double mutant (Figures 1 and 4), we predicted that SspA affects lesion formation in a H-NS-dependent manner. To address this, we infected HEp-2 cells with wild type, sspA, hns and hns $\operatorname{ssp} A$ mutant derivatives of EDL933, and determined the ability of these strains to form $\mathrm{A} / \mathrm{E}$ lesions in vitro. To this end we used the qualitative fluorescent actin staining (FAS) assay [53], where actin filaments are stained with FITC-phalloidin to detect A/E lesions that are visualized as condensed actin directly beneath adherent bacteria. Whereas infection with wild type EHEC was associated with the appearance of microcolonies of adherent bacteria and $\mathrm{A} / \mathrm{E}$ lesion formation on $70 \%$ of the HEp-2 cells (Figure 5A), the sspA mutant was unable to adhere and form A/E lesions (Figure $5 \mathrm{~B}$ ) as determined from examination of more than $50 \mathrm{HEp}-2$ cells. The A/E lesion phenotype of the sspA mutant was restored when complementing with sspA in trans from pQEsspA (Figure 5C), whereas mutant sspA supplied from
pQEsspA84-86 (Figure 5D) did not complement pedestal formation of the $s s p A$ mutant, verifying that the surfaceexposed pocket is functionally important for SspA to affect virulence of EHEC. Consistent with the finding that SspA regulates LEE expression through H-NS, the sspA mutant restored the ability to form $\mathrm{A} / \mathrm{E}$ lesions in the absence of hns in the hns sspA background as in the hns single mutant (Figure 5E-F). However, the hns sspA double mutant seemed to form A/E lesions to a higher degree than the hns single mutant, which indicates that SspA also affects the expression of virulence genes involved in $\mathrm{A} / \mathrm{E}$ lesion formation independently of the $\mathrm{H}-\mathrm{NS}$-mediated regulation. Moreover, the finding that the cell adherence ability of the $\operatorname{ssp} A$ mutant was restored when deleting hns indicates that a factor negatively regulated by $\mathrm{H}-\mathrm{NS}$ is required for the adherence of EHEC to epithelial cells. The long polar fimbria, LpfA, which is part of the H-NS/Ler regulon and is required for cell adherence of EHEC [32,54,55], might represent such a factor. Altogether, the cell adherence and A/E lesion phenotypes of the sspA mutant are consistent with the finding that SspA positively regulates the expression of genes encoding the T3SS including those of the LEE by negatively affecting H-NS levels.

The correlation between the effects of $\operatorname{ssp} A$ on the transcription of $\mathrm{H}-\mathrm{NS} / \mathrm{Ler}$-regulated virulence genes and on A/E lesion formation upon infection of HEp-2 cells supports the conclusion that SspA upregulates the expression of LEE and other virulence genes by reducing the accumulation of H-NS in the cell. A reduced cellular $\mathrm{H}-\mathrm{NS}$ level mediated by SspA will derepress the H-NS 


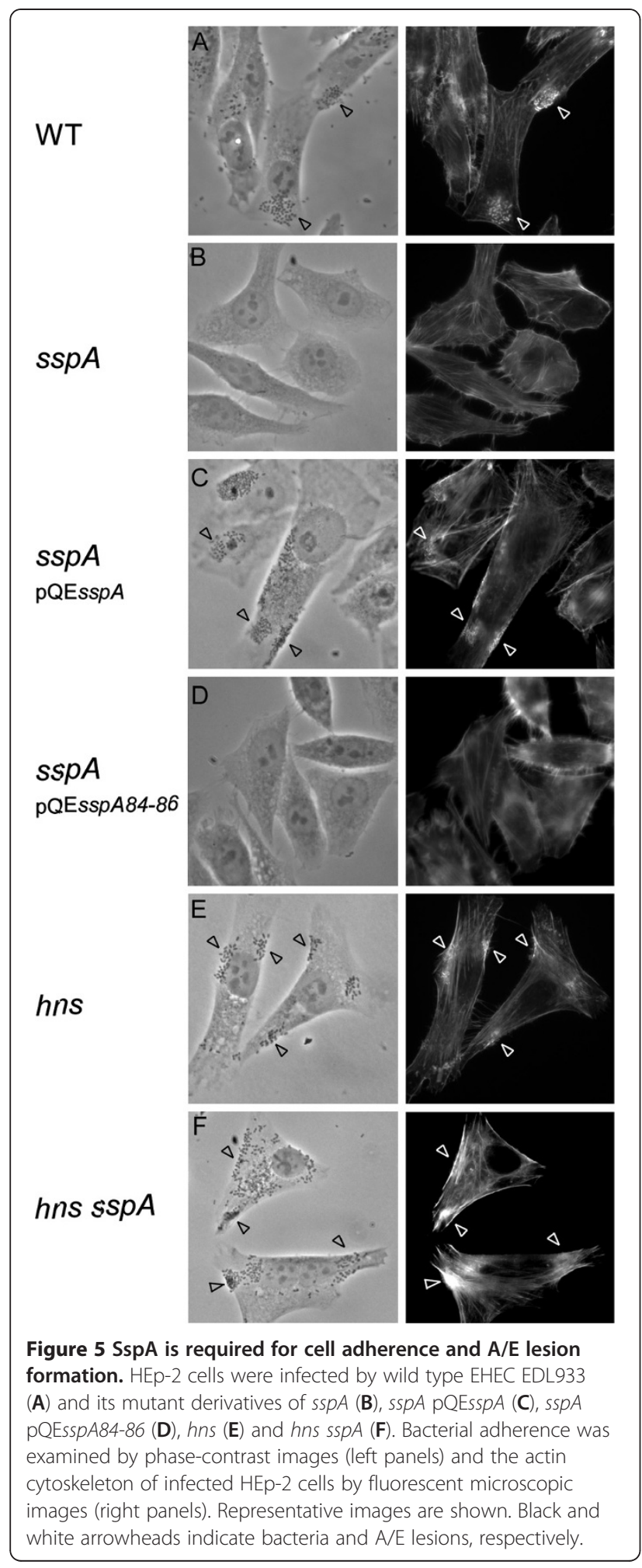

regulon and thereby allow the expression of transcriptional activators such as Ler and GrlA. These two activators then form a positive transcriptional regulatory loop partially by preventing H-NS-mediated repression [28]. Accumulation of Ler will in turn antagonize H-NS function and with that enhance the expression of virulence genes controlled by Ler [26]. At present, the molecular mechanism behind SspA-mediated regulation of the H-NS level during stationary phase and in infection to facilitate virulence gene expression in EHEC is unknown. Also, it remains to be determined whether SspA directly affects transcription of virulence genes as is the case for SspA in Francisella tularensis, where SspA along with two other transcription factors and ppGpp activates transcription to link the nutritional status to virulence gene expression [56,57].

We observed that SspA positively affects additional H-NS-controlled virulence traits of EHEC such as stationary phase-induced acid tolerance (data not shown), which enables survival of the pathogen during passage through the low $\mathrm{pH}$ environment of the human gastrointestinal tract, and thereby contributes to a low infectious dose [58,59]. Also, sspA positively affects EHEC motility (data not shown), which could influence virulence as motility enables the pathogen to penetrate the intestinal mucus layer during colonization of host cells. This further supports an important role of $\operatorname{ssp} A$ in EHEC virulence. Further experiments studying wild type and $\operatorname{ssp} A$ mutant derivatives of the A/E pathogen Citrobacter rodentium in a mouse model could help determine whether $\operatorname{ssp} A$ is required for virulence in vivo.

\section{Conclusions}

We established an important role of SspA in the regulation of LEE- and non-LEE-encoded virulence factors of a T3SS, which is important for A/E lesion formation by EHEC. SspA downregulates $\mathrm{H}-\mathrm{NS}$ levels allowing the expression of EHEC virulence genes, which are part of the H-NS/Ler regulon. Virulence genes in many bacteria are horizontally acquired genetic elements and subject to repression by H-NS. Thus, our study indicates that SspA potentially plays an important role in the pathogenicity of many bacterial pathogens in general.

\section{Methods}

\section{Standard procedures}

Standard DNA techniques, agar plates and liquid media were used as described [60]. Restriction endonucleases, T4 DNA polynucleotide kinase- and ligase (New England Biolabs) and the Expand High Fidelity PCR System (Roche Applied Sciences) were used according to manufacturer's instructions. DNA sequencing was performed by the National Cancer Institute DNA Sequencing MiniCore facility. Bacteria were grown at $37^{\circ} \mathrm{C}$ in $\mathrm{LB}$ or DMEM (Invitrogen \#11885) media supplemented with ampicillin $(100 \mu \mathrm{g} / \mathrm{ml})$, chloramphenicol $(25 \mu \mathrm{g} / \mathrm{ml})$ or kanamycin $(25 \mu \mathrm{g} / \mathrm{ml})$ as needed. HEp-2 cells (ATTC \# CCL-23) were cultured in DMEM supplemented with 10\% fetal bovine 
serum (FBS), $100 \mathrm{U} / \mathrm{ml}$ penicillin and $100 \mu \mathrm{g} / \mathrm{ml}$ streptomycin at $37^{\circ} \mathrm{C}$ in $5 \% \mathrm{CO}_{2}$.

\section{Strain and plasmid constructions}

Oligonucleotides used in this study are listed in Table 1. Gene deletions were constructed in EHEC O157:H7 EDL933 strain ATCC 700927 (Perna et al. 2001) by Lambda Red-mediated recombination using linear DNA fragments as described [61]. An in-frame deletion of sspA was created as previously described [44] resulting in strain DJ6010 (ATCC $700927 \Delta s s p A)$. The DNA fragment used for making the $s s p A$ deletion was amplified by PCR from pKD13 with primers PKD13sspAUS2 and PKD13sspADS. An hns deletion mutant derivative of strain ATCC 700927 was made by inserting a chloramphenicol resistance-encoding cat cassette, which was PCR amplified from pKD3 [61] using primers $\Delta$ hns92-1 and $\Delta$ hns92-2, $276 \mathrm{nt}$ from the hns translation initiation codon (strain DJ6011). An sspA hns double mutant (DJ6012) was constructed by introducing the $\Delta$ hns::cat deletion into strain DJ6010. All gene deletion constructs were verified by PCR amplification using primer sets sspABUS/sspABDS and hnsUS2/hnsDS2. In addition, Western blot analysis using polyclonal antibodies specific to the respective proteins confirmed the $\operatorname{ssp} A$ and hns mutant strains. Plasmid pACYCler (pDJ610) contains a $\sim 800$ bp DNA fragment encoding ler expressed from its two native promoters cloned into the HindIII/
BamHI sites of pACYC184. The DNA fragment was PCR amplified from EDL933 genomic DNA using oligos lerUS2/lerDS2.

\section{RNA isolation}

DMEM is known to enhance the expression of the T3SS, which was detrimental to growth of the hns mutant EHEC derivatives (data not shown) that already exhibit increased T3SS expression in the absence of H-NS-mediated repression. Therefore, virulence gene expression was monitored in cells grown in LB, where a mid-level expression of the T3SS occurs. Overnight cultures of wild type and mutant derivatives of EDL933 ATCC 700927 were diluted 1:1000 in $\mathrm{LB}$, supplemented with antibiotics if necessary, and grown aerobically at $37^{\circ} \mathrm{C}$ to an optical density at $600 \mathrm{~nm}$ $\left(\mathrm{OD}_{600}\right)$ of $~ 3.0$ (stationary phase). Samples of the cultures corresponding to $\sim 7.5 \times 10^{9}$ cells were collected and RNA was stabilized immediately by addition of RNAprotect bacteria reagent according to manufacturer's protocol (QIAGEN). Total RNA was purified using MasterPure ${ }^{\mathrm{TM}}$ total RNA purification kit as recommended by the manufacturer (Epicentre). Contaminating DNA in the RNA preparations was removed by DNaseI treatment. Isolated RNA was quantified based on measurements of absorption at $260 \mathrm{~nm}$. The quality of RNA was evaluated by determining the ratio of absorption at $260 \mathrm{~nm}$ and $280 \mathrm{~nm}$, which was within the preferred range of 1.7 to 2.1 , and by agarose gel electrophoresis.

Table 1 Oligonucleotide primers used in this study

\begin{tabular}{|c|c|c|}
\hline Application & Name & Oligonucleotide sequence $\left(5^{\prime}\right.$ to $\left.3^{\prime}\right)$ \\
\hline \multirow[t]{8}{*}{ Strain construction } & PKD13sspAUS2 & ACTATCATCCAATTTTCTGCCCAAATGTCGGGTATTGCTCAGGAGGTTTCTTTCATGATGTCCGGGGATCCGTCGACCTGC \\
\hline & PKD13sspADS & AGATTAACTCCGGCCCAGACGCATTTCACGTTCTGCTTCAGTGTAGGCTGGAGCTGCTTCGA \\
\hline & sspABUS & GATTGGATCCGGCTTCGTTACTCGTGACGCT \\
\hline & sspABDS & GATTGAAGCTTACTTCACAACGCGTAATGC \\
\hline & hns $\Delta 92-1$ & GAGCTGCTGAATAGCCTTGCCGCCGTTAAATCTGGCACCAAAGCTAAACGTGCTTGTGTAGGCTGGAGCTGCTTCG \\
\hline & hns $\Delta 92-2$ & GGTTTAGTTCGCCGTTTCGTCAACGTAGCTATATTTTGCCGGACGCTTATGAATATCCTCCTTAGTTC \\
\hline & hnsUS2 & CCATGGAATTCACCATGAGCGAAGCACTTAAAATTCTGAACA \\
\hline & hnsDS2 & CCAGGTCTGCAGTTATTGCTTGATCAGGAAATCG \\
\hline \multirow[t]{2}{*}{ Plasmid construction } & lerUs2 & GATTGGATCCGCTGCGACTGCGTTCGCTTGCT \\
\hline & lerDS2 & GATTGAAGCTTCCAGCTCAGTTATCGTTAT \\
\hline \multirow[t]{9}{*}{ Primer extension } & lerPE & GCTTCCTGCTGTAGA \\
\hline & LEE2PE & GCTGCTTCCATTGATCTTTCTCC \\
\hline & LEE3PE & CAATTTCAACACGGTTATC \\
\hline & LEE4PE & CAGATGCGGGGTTITGATTAAATTC \\
\hline & LEE5PE & CATTGGGATTATGACCAAGA \\
\hline & mapPE & GGACTAAACATGCTATAAACC \\
\hline & grIRPE & CCTTCCCCACAGGAGTCTTC \\
\hline & stcEPE & GGCAAGGATCGTACATGA \\
\hline & ompAPE & ACGAGATAACACGGTTAAATCC \\
\hline
\end{tabular}




\section{Primer extension analysis}

Primer extension reactions were carried out on $8 \mu \mathrm{g}$ of total RNA using the AMV reverse transcriptase primer extension system according to manufacturer's instructions (Promega). The ${ }^{32}$ P-labeled DNA oligos (1 pmol) were used to detect the transcripts of interest: lerPE (LEE1/ler), LEE2PE (LEE2/espZ), LEE3PE (LEE3/mpc), LEE4PE (LEE4/sepL), LEE5PE (LEE5/tir), mapPE (map), grlRPE ( $g r l R A)$ and stcEPE (stcE). The ${ }^{32} \mathrm{P}$-labeled DNA oligo ompAPE was used as an internal control in each extension reaction to detect the transcripts from ompA $\mathrm{P} 1$ and P2. The DNA oligos were 5'-end labeled with $\left(\gamma^{-32} \mathrm{P}\right)$ ATP (GE Healthcare) using T4 polynucleotide kinase (New England Biolabs). The cDNA products were separated on a $6 \%$ denaturating gel along with a labeled $\phi X 174$ hinfI DNA size marker (Promega) and visualized by autoradiography. The lengths of the cDNA transcripts ler, espZ, mpc, sepL, tir, map, grlRA, stcE, ompA P1, and ompA P2 were around 250, 120, 147, 122, 142, 135, 162, 125, 89 and 93 nt, respectively. No DNA product was detected in the absence of RNA. Transcript levels were quantified using ImageJ software [62] and normalized to ompA transcript levels. The primer extension experiments were carried out at least twice and similar results were obtained.

\section{Western analysis}

Total protein was prepared from cultures grown in LB at $37^{\circ} \mathrm{C}$ to $\mathrm{OD}_{600} \sim 3.0$. Samples containing equal amounts of total protein equivalent to $0.03 \mathrm{OD}_{600}$ units of cell culture were prepared and analyzed essentially as previously described [44]. Polyclonal antibodies against H-NS or Fis were used to detect the respective proteins. The western blots were developed using ECL plus reagents (GE Healthcare) and quantified with a FluorChem imaging system (Alpha Innotech). The western analysis was carried out at least twice, and similar results were obtained.

\section{Assay for the presence of A/E lesions on HEp-2 cells} The ability of EHEC EDL933 (ATCC 700927) wild type and its mutant derivatives to adhere and form $\mathrm{A} / \mathrm{E}$ lesions on HEp-2 cell monolayers was evaluated using the fluorescent actin staining assay as described [53]. Bacterial cells were grown without aeration for 16-18 h at $37^{\circ} \mathrm{C}$ in tryptic soy broth that was supplemented with antibiotics if needed. Prior to infection cells were diluted 1:5 in infection medium (DMEM supplemented with $2 \%$ FBS and $0.5 \%$ mannose) and incubated at $37^{\circ} \mathrm{C} 5 \% \mathrm{CO}_{2}$ for $2 \mathrm{~h}$. About $2 \times 10^{6}$ bacteria (M.O.I. 10) in $100 \mu \mathrm{l}$ were added to semi-confluent HEp-2 cell monolayers grown on glass coverslips in a 6-well plate (Multiwell ${ }^{\mathrm{TM}}$ Falcon \#353046). After infection for 4-5 h, monolayers were fixed with $4 \%$ formamide in PBS, washed three times with PBS, permeabilized with $0.1 \%$ Triton X-100 in
PBS, and then stained with Alexa Fluor 488 phalloidin (Invitrogen). Coverslips were mounted on slides using Prolong Gold antifade reagent (Invitrogen) and the edges of the coverslip were sealed with cytoseal-60 (RichardAllan Scientific). The samples were visualized using a Zeiss Axiophot II microscope equipped with a 40X objective, epifluorescence filters and a 1.25 optovar (Carl Zeiss MicroImaging Inc.). Images were captured with a charge-coupled device camera (Micromax) using IPL lab software. For each bacterial strain the assay was carried out independently at least three times and at least $50 \mathrm{HEp}-2$ cells were visually examined.

\section{Competing interests}

The authors declare that they have no competing interests.

\section{Authors' contributions}

Experiments were designed by $\mathrm{AH}$ and DJ. Experiments were performed by $\mathrm{AH}$. The manuscript was written by $\mathrm{AH}$ and DJ. Both authors have read and approved the final manuscript.

\section{Acknowledgements}

We thank Darren Sledjeski for the antiserum against H-NS. We also thank lab members for interaction and discussion during the course of the study. This work was supported by the Intramural Research Program of the $\mathrm{NIH}$, National Cancer Institute, Center for Cancer Research.

\section{Author details}

${ }^{1}$ Transcription Control Section, Gene Regulation and Chromosome Biology Laboratory, Frederick National Laboratory for Cancer Research, National Cancer Institute, National Institutes of Health, Frederick, MD 21702, USA. ${ }^{2}$ Present Address: Department of Microbiology and Immunology, University of Maryland School of Medicine, Baltimore, MD 21201, USA.

Received: 25 July 2012 Accepted: 9 October 2012 Published: 11 October 2012

\section{References}

1. Nataro JP, Kaper JB: Diarrheagenic Escherichia coli. Clin Microbiol Rev 1998 11:142-201.

2. Karmali MA: Infection by Shiga toxin-producing Escherichia coli: an overview. Mol Biotechnol 2004, 26:117-122.

3. Frankel G, Phillips AD, Rosenshine I, Dougan G, Kaper JB, Knutton S: Enteropathogenic and enterohaemorrhagic Escherichia coli: more subversive elements. Mol Microbiol 1998, 30:911-921.

4. Jerse $A E, Y u J$, Tall BD, Kaper JB: A genetic locus of enteropathogenic Escherichia coli necessary for the production of attaching and effacing lesions on tissue culture cells. Proc Natl Acad Sci USA 1990, 87:7839-7843.

5. McDaniel TK, Jarvis KG, Donnenberg MS, Kaper JB: A genetic locus of enterocyte effacement conserved among diverse enterobacterial pathogens. Proc Natl Acad Sci USA 1995, 92:1664-1668.

6. Huys G, Cnockaert M, Janda JM, Swings J: Escherichia albertii sp. nov., a diarrhoeagenic species isolated from stool specimens of Bangladeshi children. Int J Syst Evol Microbiol 2003, 53:807-810.

7. Rasko DA, Rosovitz MJ, Myers GS, Mongodin EF, Fricke WF, Gajer P, Crabtree J, Sebaihia M, Thomson NR, Chaudhuri R, et al: The pangenome structure of Escherichia coli: comparative genomic analysis of $E$. coli commensal and pathogenic isolates. J Bacteriol 2008, 190:6881-6893.

8. Jarvis KG, Giron JA, Jerse AE, McDaniel TK, Donnenberg MS, Kaper JB: Enteropathogenic Escherichia coli contains a putative type III secretion system necessary for the export of proteins involved in attaching and effacing lesion formation. Proc Natl Acad Sci USA 1995, 92:7996-8000.

9. Elliott SJ, Wainwright LA, McDaniel TK, Jarvis KG, Deng YK, Lai LC, MCNamara BP, Donnenberg MS, Kaper JB: The complete sequence of the locus of enterocyte effacement (LEE) from enteropathogenic Escherichia coli E2348/69. Mol Microbiol 1998, 28:1-4. 
10. Garmendia J, Frankel G, Crepin VF: Enteropathogenic and enterohemorrhagic Escherichia coli infections: translocation, translocation, translocation. Infect Immun 2005, 73:2573-2585.

11. Mellies $\mathrm{L}$, Barron AM, Carmona AM: Enteropathogenic and enterohemorrhagic Escherichia coli virulence gene regulation. Infect Immun 2007, 75:4199-4210.

12. Tsai NP, Wu YC, Chen JW, Wu CF, Tzeng CM, Syu WJ: Multiple functions of 10036 in the regulation of the pathogenicity island of enterohaemorrhagic Escherichia coli 0157:H7. Biochem J 2006, 393:591-599.

13. Perna NT, Mayhew GF, Posfai G, Elliott S, Donnenberg MS, Kaper JB, Blattner FR: Molecular evolution of a pathogenicity island from enterohemorrhagic Escherichia coli O157:H7. Infect Immun 1998, 66:3810-3817.

14. Kaper JB, Nataro JP, Mobley HL: Pathogenic Escherichia coli. Nat Rev Microbiol 2004, 2:123-140.

15. Navarre WW, McClelland M, Libby SJ, Fang FC: Silencing of xenogeneic DNA by $\mathrm{H}-\mathrm{NS}$-facilitation of lateral gene transfer in bacteria by a defense system that recognizes foreign DNA. Genes Dev 2007, 21:1456-1471

16. Atlung T, Ingmer H: H-NS: a modulator of environmentally regulated gene expression. Mol Microbiol 1997, 24:7-17

17. Falconi M, Colonna B, Prosseda G, Micheli G, Gualerzi CO: Thermoregulation of Shigella and Escherichia coli EIEC pathogenicity. A temperature-dependent structural transition of DNA modulates accessibility of virF promoter to transcriptional repressor H-NS. EMBO J 1998, 17:7033-7043.

18. Rowe S, Hodson N, Griffiths G, Roberts IS: Regulation of the Escherichia coli K5 capsule gene cluster: evidence for the roles of H-NS, BipA, and integration host factor in regulation of group 2 capsule gene clusters in pathogenic E. coli. J Bacteriol 2000, 182:2741-2745.

19. Muller CM, Dobrindt U, Nagy G, Emody L, Uhlin BE, Hacker J: Role of histone-like proteins $\mathrm{H}-\mathrm{NS}$ and StpA in expression of virulence determinants of uropathogenic Escherichia coli. J Bacteriol 2006, 188:5428-5438.

20. Erol I, Jeong KC, Baumler DJ, Vykhodets B, Choi SH, Kaspar CW: H-NS controls metabolism and stress tolerance in Escherichia coli 0157: $\mathrm{H} 7$ that influence mouse passage. BMC Microbiol 2006, 6:72

21. Navarre WW, Porwollik S, Wang Y, McClelland M, Rosen H, Libby SJ, Fang FC: Selective silencing of foreign DNA with low GC content by the H-NS protein in Salmonella. Science 2006, 313:236-238.

22. Lucchini S, Rowley G, Goldberg MD, Hurd D, Harrison M, Hinton JC: $\mathrm{H}$-NS mediates the silencing of laterally acquired genes in bacteria. PLoS Pathog 2006, 2:e81.

23. Fang FC, Rimsky S: New insights into transcriptional regulation by H-NS. Curr Opin Microbiol 2008, 11:113-120.

24. Ali SS, Xia B, Liu J, Navarre WW: Silencing of foreign DNA in bacteria. Curr Opin Microbiol 2012, 15:175-181.

25. Dorman CJ: H-NS: a universal regulator for a dynamic genome. Nat Rev Microbiol 2004, 2:391-400.

26. Bustamante VH, Santana FJ, Calva E, Puente JL: Transcriptional regulation of type III secretion genes in enteropathogenic Escherichia coli: Ler antagonizes H-NS-dependent repression. Mol Microbiol 2001, 39:664-678.

27. Haack KR, Robinson CL, Miller KJ, Fowlkes JW, Mellies JL: Interaction of Ler at the LEE5 (tir) operon of enteropathogenic Escherichia coli. Infect Immun 2003, 71:384-392.

28. Barba J, Bustamante VH, Flores-Valdez MA, Deng W, Finlay BB, Puente JL: A positive regulatory loop controls expression of the locus of enterocyte effacement-encoded regulators Ler and GrlA. J Bacteriol 2005, 187:7918-7930.

29. Umanski T, Rosenshine I, Friedberg D: Thermoregulated expression of virulence genes in enteropathogenic Escherichia coli. Microbiology 2002, 148:2735-2744

30. Laaberki MH, Janabi N, Oswald E, Repoila F: Concert of regulators to switch on LEE expression in enterohemorrhagic Escherichia coli 0157:H7: interplay between Ler, GrIA, HNS and RpoS. Int J Med Microbiol 2006, 296:197-210.

31. Sanchez-SanMartin C, Bustamante VH, Calva E, Puente JL: Transcriptional regulation of the orf19 gene and the tir-cesT-eae operon of enteropathogenic Escherichia coli. J Bacteriol 2001, 183:2823-2833.

32. Torres $A G$, Slater $T M$, Patel SD, Popov VL, renas-Hernandez MM: Contribution of the Ler- and H-NS-regulated long polar fimbriae of Escherichia coli 0157:H7 during binding to tissue-cultured cells. Infect Immun 2008, 76:5062-5071.
33. Rogers MT, Zimmerman R, Scott ME: Histone-like nucleoid-structuring protein represses transcription of the ehx operon carried by locus of enterocyte effacement-negative Shiga toxin-expressing Escherichia coli. Microb Pathog 2009, 47:202-211.

34. Roe AJ, Yull H, Naylor SW, Woodward MJ, Smith DG, Gally DL: Heterogeneous surface expression of EspA translocon filaments by Escherichia coli 0157:H7 is controlled at the posttranscriptional level. Infect Immun 2003, 71:5900-5909.

35. Stoebel DM, Free A, Dorman CJ: Anti-silencing: overcoming $\mathrm{H}-\mathrm{NS}$-mediated repression of transcription in Gram-negative enteric bacteria. Microbiology 2008, 154:2533-2545.

36. Mellies JL, Elliott SJ, Sperandio V, Donnenberg MS, Kaper JB: The Per regulon of enteropathogenic Escherichia coli: identification of a regulatory cascade and a novel transcriptional activator, the locus of enterocyte effacement (LEE)-encoded regulator (Ler). Mol Microbio/ 1999, 33:296-306.

37. Elliott SJ, Sperandio V, Giron JA, Shin S, Mellies JL, Wainwright L, Hutcheson SW, McDaniel TK, Kaper JB: The locus of enterocyte effacement (LEE)-encoded regulator controls expression of both LEE- and non-LEE-encoded virulence factors in enteropathogenic and enterohemorrhagic Escherichia coli. Infect Immun 2000, 68:6115-6126.

38. Sperandio V, Mellies JL, Delahay RM, Frankel G, Crawford JA, Nguyen W, Kaper JB: Activation of enteropathogenic Escherichia coli (EPEC) LEE2 and LEE3 operons by Ler. Mol Microbiol 2000, 38:781-793.

39. Mellies JL, Larabee FJ, Zarr MA, Horback KL, Lorenzen E, Mavor D: Ler interdomain linker is essential for anti-silencing activity in enteropathogenic Escherichia coli. Microbiology 2008, 154:3624-3638.

40. Ishihama A, Saitoh T: Subunits of RNA polymerase in function and structure. IX. Regulation of RNA polymerase activity by stringent starvation protein (SSP). J Mol Biol 1979, 129:517-530.

41. Williams MD, Fuchs JA, Flickinger MC: Null mutation in the stringent starvation protein of Escherichia coli disrupts lytic development of bacteriophage P1. Gene 1991, 109:21-30.

42. Williams MD, Ouyang TX, Flickinger MC: Starvation-induced expression of SspA and SspB: the effects of a null mutation in sspA on Escherichia coli protein synthesis and survival during growth and prolonged starvation. Mol Microbiol 1994, 11:1029-1043.

43. Hansen AM, Lehnherr H, Wang X, Mobley V, Jin DJ: Escherichia coli SspA is a transcription activator for bacteriophage $\mathrm{P} 1$ late genes. Mol Microbiol 2003, 48:1621-1631.

44. Hansen AM, Qiu Y, Yeh N, Blattner FR, Durfee T, Jin DJ: SspA is required for acid resistance in stationary phase by downregulation of $\mathrm{H}-\mathrm{NS}$ in Escherichia coli. Mol Microbiol 2005, 56:719-734.

45. Hansen AM, Gu Y, Li M, Andrykovitch M, Waugh DS, Jin DJ, Ji X: Structural basis for the function of stringent starvation protein a as a transcription factor. J Biol Chem 2005, 280:17380-17391.

46. De Reuse H, Taha MK: RegF, an SspA homologue, regulates the expression of the Neisseria gonorrhoeae pilE gene. Res Microbiol 1997, 148:289-303.

47. Badger JL, Young BM, Darwin AJ, Miller VL: Yersinia enterocolitica ClpB affects levels of invasin and motility. J Bacteriol 2000, 182:5563-5571.

48. Baron GS, Nano FE: MgIA and MgIB are required for the intramacrophage growth of Francisella novicida. Mol Microbiol 1998, 29:247-259.

49. Lauriano CM, Barker JR, Yoon SS, Nano FE, Arulanandam BP, Hassett DJ, Klose KE: MglA regulates transcription of virulence factors necessary for Francisella tularensis intraamoebae and intramacrophage survival. Proc Natl Acad Sci USA 2004, 101:4246-4249.

50. Merrell DS, Hava DL, Camilli A: Identification of novel factors involved in colonization and acid tolerance of Vibrio cholerae. Mol Microbiol 2002, 43:1471-1491.

51. Xu Q, Dziejman M, Mekalanos JJ: Determination of the transcriptome of Vibrio cholerae during intraintestinal growth and midexponential phase in vitro. Proc Natl Acad Sci USA 2003, 100:1286-1291.

52. Perna NT, Plunkett G III, Burland V, Mau B, Glasner JD, Rose DJ, Mayhew GF, Evans PS, Gregor J, Kirkpatrick HA, et al: Genome sequence of enterohaemorrhagic Escherichia coli O157:H7. Nature 2001, 409:529-533.

53. Knutton S, Baldwin T, Williams PH, McNeish AS: Actin accumulation at sites of bacterial adhesion to tissue culture cells: basis of a new diagnostic test for enteropathogenic and enterohemorrhagic Escherichia coli. Infect Immun 1989, 57:1290-1298.

54. Torres AG, Giron JA, Perna NT, Burland V, Blattner FR, velino-Flores F, Kaper JB: Identification and characterization of IpfABCC'DE, a fimbrial operon of enterohemorrhagic Escherichia coli 0157:H7. Infect Immun 2002, 70:5416-5427. 
55. Torres AG, Lopez-Sanchez GN, Milflores-Flores L, Patel SD, Rojas-Lopez M, Martinez de la Pena CF, renas-Hernandez MM, Martinez-Laguna Y: Ler and H-NS, regulators controlling expression of the long polar fimbriae of Escherichia coli 0157:H7. J Bacteriol 2007, 189:5916-5928.

56. Charity JC, Costante-Hamm MM, Balon EL, Boyd DH, Rubin EJ, Dove SL: Twin RNA polymerase-associated proteins control virulence gene expression in Francisella tularensis. PLoS Pathog 2007, 3:e84.

57. Charity JC, Blalock LT, Costante-Hamm MM, Kasper DL, Dove SL: Small molecule control of virulence gene expression in Francisella tularensis. PLoS Pathog 2009, 5:e1000641.

58. Peterson WL, Mackowiak PA, Barnett CC, Marling-Cason M, Haley ML: The human gastric bactericidal barrier: mechanisms of action, relative antibacterial activity, and dietary influences. J Infect Dis 1989, 159:979-983.

59. Lin J, Lee IS, Frey J, Slonczewski JL, Foster JW: Comparative analysis of extreme acid survival in Salmonella typhimurium, Shigella flexneri, and Escherichia coli. J Bacteriol 1995, 177:4097-4104.

60. Sambrook J, Russell DW: Molecular cloning: a laboratory manual. Cold Spring Harbor, N.Y:: Cold Spring Harbor Laboratory; 2001.

61. Datsenko KA, Wanner BL: One-step inactivation of chromosomal genes in Escherichia coli K-12 using PCR products. Proc Natl Acad Sci USA 2000, 97:6640-6645.

62. Abramoff MD, Magalhaes PJ, Ram SJ: Image Processing with ImageJ. Biophoton Int 2004, 11(7):36-42.

doi:10.1186/1471-2180-12-231

Cite this article as: Hansen and Jin: SspA up-regulates gene expression of the LEE pathogenicity island by decreasing H-NS levels in enterohemorrhagic Escherichia coli. BMC Microbiology 2012 12.231.

\section{Submit your next manuscript to BioMed Central and take full advantage of:}

- Convenient online submission

- Thorough peer review

- No space constraints or color figure charges

- Immediate publication on acceptance

- Inclusion in PubMed, CAS, Scopus and Google Scholar

- Research which is freely available for redistribution 